Proceedings

\title{
Analysis of the relationship between coastal development and the alteration of beach shorelines: a retrospective view based on spatial indicators
}

\author{
Francisco Javier Gómez ${ }^{1, *}$ and Salvador García-Ayllón ${ }^{2}$ \\ 1 Technical University of Cartagena; gomezjimenezfj@gmail.com \\ 2 Technical University of Cartagena; salvador.ayllon@upct.es \\ * Correspondence: angela.franco@edu.upct.es
}

Citation: Gomez, F.J.; García-Ayllón, S.,2022, Analysis of the relationship between coastal development and the alteration of beach shorelines: a retrospective view based on spatial indicators. SUPTM 2022 conference proceedings sciforum-054503.

https://doi.org/10.31428/10317/10608 Publisher's Note: UPCT and Sciforum stays neutral with regard to jurisdictional claims in published maps and institutional affiliations.

Copyright: @ $₫ 2022$ by the authors. Submitted for possible open access publication under the terms and conditions of the Creative Commons Attribution (CC BY) license (https://creativecommons.org/licens es/by/4.0/).

\begin{abstract}
The construction of port infrastructures in urbanized coastal territories causes a great impact in the short and long term. The analysis of this impact is a very complex field due to the high number of variables involved. The criteria for analyzing these phenomena are usually based on the characteristics of the infrastructure to be built, but in the case of highly urbanized areas, there are other variables that are not normally taken into account. With the aim of giving an alternative approach to traditional analysis methods and relating the maximum number of possible variables, our study is given a multiparametric and retrospective approach based on GIS indicators. For this, the coastal area of the southeast of Spain is analyzed with the cartographic information that we have from the last 50 years. The changes suffered in the coastline caused by the construction of ports are analyzed in two dimensions and the statistical correlation of the different variables studied and the impact suffered on the coast are studied, such as the formation of tombolos and hemitombolos or salients, as well as coastal regression, even generation of sludge due to imbalances in sedimentary dynamics. The results can be used to enrich and improve the traditional analysis models for singular cases such as those studied.
\end{abstract}

Keywords: Shoreline impacts; urban port areas; coastal dynamics; spatial analysis; geostatistics.

\section{Introduction}

The analysis of anthropic impacts on the coastline has been widely studied from the point of view of the generation of port infrastructures [1]. There are both direct and indirect, deterministic and semi-probabilistic, etc. approaches of the dynamics of the coast [2]. These approaches focus their analysis of the impacts on sedimentary dynamics on models developed from climatological or endogenous variables of the design of the port infrastructure itself, such as fetch, the statistical height of the design wave, the bathymetry or the orientation of the dikes [3].

This approach, traditional in civil engineering, often have difficulty incorporating other parameters collateral to the port infrastructure itself, focusing the analysis primarily on the design of the port construction, and these parameters may be relevant in certain contexts. In addition, these are usually theoretical-practical approaches that are difficult to contrast with reality, since the effects of the construction of port infrastructures in the coastal area usually manifest themselves over several years, or even decades.

In this sense, the urban and territorial environment on which the port is located, the orographic contextualization of the infrastructure or the interrelation with other nearby coastal infrastructures are parameters that usually acquire a secondary role in the traditional analysis models of anthropic impacts in sedimentary dynamics, when they are not directly ignored. For this reason, a different approach, multiparametric and based on georeferenced spatial indicators, which will be evaluated over time, is proposed to evaluate these impacts. 
This approach based on spatio-temporal GIS indicators will allow to carry out a work of contrast with the more direct and short-term reality. For this, a series of ports located in the southeast Mediterranean of Spain has been analyzed. These urban ports areas offer a varied catalogue of boundary conditions, alternating different port construction typologies, location and geographical orientations, form of insertion on the coastline or interrelation with the urban fabric. Based on the observed evolution of the littoral space during the last 50 years, the existing correlation between the different configuration parameters of the urban port areas and their effects on the surrounding coastal environment will be analyzed, in order to determine which spatial and territorial parameters govern these effects.

\section{Area of study}

The selected study area is located in the southeast of the Mediterranean coast of Spain. This strip of about $300 \mathrm{~km}$ includes the regions of Alicante, Murcia and Almería. It is a territory with a high number of urban areas with port infrastructures and a varied catalog of different configurations (Figure 1).

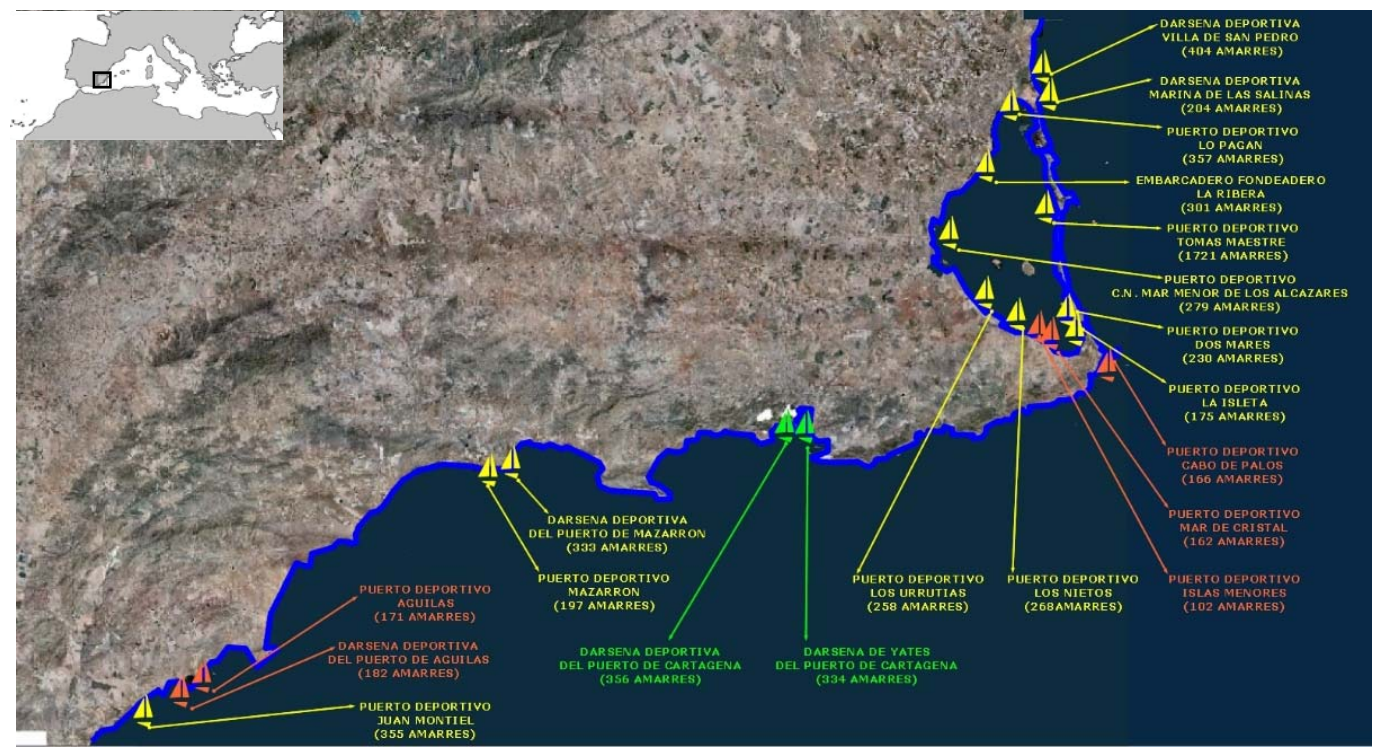

Figure 1. Port areas in the coastal territory of the Region of Murcia. Source: CARM.

In this geographical area we find port areas of varied characteristics. In relation to the level of insertion on the coastline, we find ports of traditional configuration with dike and counterdike generating a space on land reclaimed from the sea such as the Port of San Pedro del Pinatar, ports with their dock completely integrated within the land space such as the from Cabo de Palos and island ports such as Puerto de Los Nietos located in the marine environment (see figure 2).

At the level of the marine environment, two well differentiated areas have been analyzed: on the one hand, the ports located in the Mediterranean Sea where the waves, without having the impact of an oceanic climate, are a determining element in the configuration of the port. On the other hand, the Mar Menor, a coastal lagoon of $170 \mathrm{~km}^{2}$ and average drafts of 4-5 m deep, where we find nine marinas in which the reduced waves are not a determining element in the design of their configuration.

In relation to its anthropic interaction with the closer coastal dynamics, we find ports located at the mouths of channels or rivers, such as Guardamar de Segura in Alicante, ports for which it has been necessary to dredge the land or a channel such as the ports of La Isleta or Tomas Maestre, and ports generated almost naturally by a bay like Cartagena. Finally, regarding the existence of a spatial interaction with the urban fabric, we find a wide variety in the casuistry. There are ports fully integrated into urban environments 
such as Lo Pagan or Águilas, ports partially integrated with non-urbanized areas or beach areas such as Mazarrón, and ports only surrounded by non-urbanized or even environmentally protected areas such as San Pedro del Pinatar. These four parameters will serve as the basis for shaping our methodological proposal.

\section{Methodology}

Considering the characteristics of the study area described in the previous section, a methodological approach will be carried out in which the parameters mentioned above will be categorized through qualitative indicators of the characteristics of the port environments. Next, some geo-referenced indicators of the different effects that have been detected in the spatiotemporal analysis carried out in the study area during the last 50 years will be described.

Finally, a geostatistical analysis will be established between the different combinations of qualitative indicators of configuration spatial indicators of effects in the coastal environment to try to understand from a spatio-temporal perspective which parameters govern the effects of and the port infrastructures in the urban coastal environments of this study area.

\subsection{Spatial indicators of port areas configuration}

The parameters analyzed are described below:

- Insertion level on the coastline ILC: This parameter measures the level of territorial insertion of the port area on the coastline. It is classified into 3 levels. The high level is assigned to those port areas that are completely generated in the land zone without the need to gain space from the sea. The middle level is assigned to those port areas that are partially located in the land area, with their dock occupying excavated space behind the coastline. The low level is assigned to those port areas whose basin has been generated entirely on reclaimed land beyond the coastline.

- Marine environment $M E$ : this parameter analyses the maritime variable, dividing it into two cases. On the one hand, the ports located in the Mediterranean Sea where the waves significantly condition the constructive design of the port infrastructure. On the other hand, the ports located in the Mar Menor, where the waves hardly influence the configuration of the port area.

- Anthropic interaction with the closer coastal dynamics AICCD: this parameter analyzes the interaction capacity of the transformation of the port area with the infrastructures closest to it. The ability to generate synergies between nearby coastal disturbances can have an impact greater than the simple sum of both.

- Spatial Interaction with urban environment SIUE: This parameter analyzes from a spatial perspective the interaction between the port infrastructure and the surrounding urban environment, if there is one. The fit in the urban fabric of the port basin is also addressed as a parameter, measuring the level of interlocking of the connections at the urban level.

\subsection{GIS impact indicators on the coastal territory of port infrastructures}

To analyse the effects of the different casuistry of the proposed port areas, four georeferenced spatial analysis indices have been generated. These indices address from a territorial perspective the different impacts that the transformation of the coast may generate on the environment due to the construction of port infrastructures. The indices used are detailed below:

- Index of sedimentary imbalance generation $I_{S I G}$

- Index of generation of environmental imbalances $I_{G E I}$

- Index of deferred direct affection to urban environments $I_{D D A U E}$

- Index of deferred affection to distant urban areas $I_{D A D U A}$ 


\subsection{Geostatistical analysis}

To analyze the level of spatial correlation between the two types of parameters described in the previous sections, a geostatistical analysis will be used [4]. This analysis will allow us to understand from a spatial perspective what are the behavior patterns of the impacts suffered by the coastal territory over time, based on the various characteristics of creation and transformation of port areas.

\section{Results and Discussion}

This research is still in an initiation phase as part of a doctoral thesis. The objective is to correlate the urban configuration of the coastal actuarial areas, observing how in the areas with greater exposure due to the occupation of the water surface there have been greater alterations, and to what extent other variables such as waves, the orientation or urban configuration of the port area influences alterations in sedimentary dynamics in the long term.

The results obtained will serve as a guide for the design and planning of ports in coastal areas with similar boundary conditions to the studied in the Mediterranean coast. In this context, the use of his tools can be of great help for the long-term evaluation of the implications that port design has on the urban areas, conditioning the effects that the future may produce on the present execution of port infrastructures in cities.

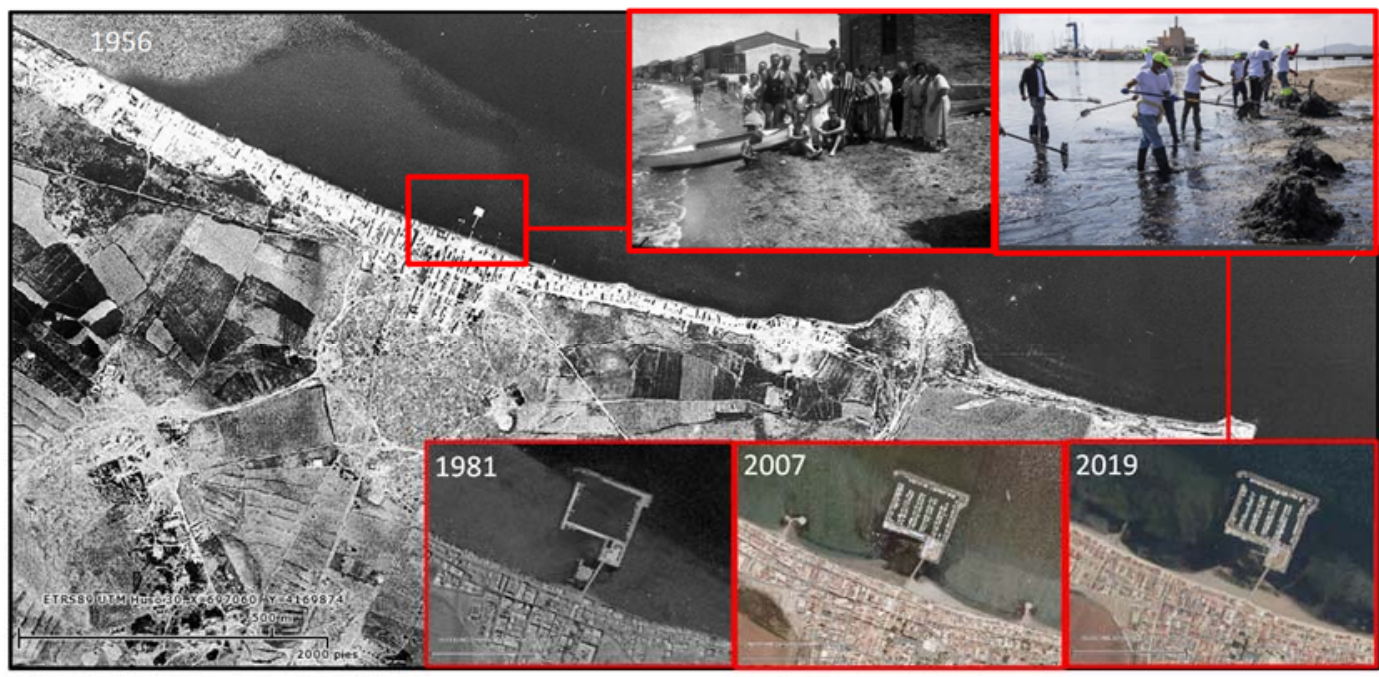

Figure 2. Spatial analysis of the evolution of the impact of island-type port infrastructure in the town of Los Nietos between 1956 and 2019.

Funding: This research received no external funding.

Conflicts of Interest: The authors declare no conflict of interest.

\section{References}

1. Bianco, F.; Conti, P.; García-Ayllon, S.; Pranzini, E. An Integrated Approach to Analyze Sedimentary Stock and Coastal Erosion in Vulnerable Areas: Resilience Assessment of San Vicenzo's Coast (Italy). Water 2020, 12, doi:10.3390/w12030805.

2. Bianco, F.; García-Ayllón, S. Coastal resilience potential as an indicator of social and morphological vulnerability to beach management. Estuar. Coast. Shelf Sci. 2021, 253, 107290, doi:https://doi.org/10.1016/j.ecss.2021.107290.

3. García-Ayllón, S. Integrated management in coastal lagoons of highly complexity environments: Resilience comparative analysis for three case-studies. Ocean Coast. Manag. 2017, 143, doi:10.1016/j.ocecoaman.2016.10.007.

4. Garcia-Ayllon, S.; Radke, J. Geostatistical Analysis of the Spatial Correlation between Territorial Anthropization and Flooding Vulnerability: Application to the DANA Phenomenon in a Mediterranean Watershed. Appl. Sci. 2021, 11, 809, doi:10.3390/app11020809. 